\title{
Three-dimensional morphological and positional analysis of the temporomandibular joint in adults with posterior crossbite: A cross-sectional comparative study
} DOI:

10.1111/joor.13156

\section{Document Version}

Accepted author manuscript

Link to publication record in Manchester Research Explorer

Citation for published version (APA):

Almaqrami, B. S., Alhammadi, M. S., Tang, B., ALyafrusee, E. S., Hua, F., \& He, H. (2021). Three-dimensional morphological and positional analysis of the temporomandibular joint in adults with posterior crossbite: A crosssectional comparative study. Journal of Oral Rehabilitation. https://doi.org/10.1111/joor.13156

Published in:

Journal of Oral Rehabilitation

\section{Citing this paper}

Please note that where the full-text provided on Manchester Research Explorer is the Author Accepted Manuscript or Proof version this may differ from the final Published version. If citing, it is advised that you check and use the publisher's definitive version.

\section{General rights}

Copyright and moral rights for the publications made accessible in the Research Explorer are retained by the authors and/or other copyright owners and it is a condition of accessing publications that users recognise and abide by the legal requirements associated with these rights.

\section{Takedown policy}

If you believe that this document breaches copyright please refer to the University of Manchester's Takedown Procedures [http://man.ac.uk/04Y6Bo] or contact uml.scholarlycommunications@manchester.ac.uk providing relevant details, so we can investigate your claim.

\section{OPEN ACCESS}


PROF. HONG HE (Orcid ID : 0000-0002-9234-0015)

Article type : Original Article

\title{
Three-dimensional morphological and positional analysis of the temporomandibular joint in adults with posterior crossbite: A cross-sectional comparative study
}

\author{
Running title TMJ in patients with posterior crossbite
}

Bushra Sufyan Almaqrami 1,2; Maged Sultan Alhammadi 3; Bojun Tang 1; Enas Senan ALyafrusee 2,4; Fang Hua 1,5,6 ; Hong He $1, *$

1. Department of Orthodontics, Hubei-MOST KLOS \& KLOBM, School \& Hospital of Stomatology, Wuhan University, Wuhan, China.

2. Department of Orthodontics and Dentofacial Orthopedics, Faculty of Dentistry, Ibb University, Republic of Yemen.

3. Division of Orthodontics and Dentofacial Orthopedics, Department of Preventive Dental Sciences, Faculty of Dentistry, Jazan University, Jazan, Saudi Arabia.

4. Orthodontic Department, School of Stomatology Lanzhou University, Lanzhou, China.

5. Center for Evidence-Based Stomatology, Hubei-MOST KLOS \& KLOBM, School \& Hospital of Stomatology, Wuhan University, Wuhan, China.

6. Division of Dentistry, School of Medical Sciences, Faculty of Biology, Medicine and Health, University of Manchester, Manchester Academic Health Science Centre, Manchester, UK.

Corresponding author:

This article has been accepted for publication and undergone full peer review but has not been through the copyediting, typesetting, pagination and proofreading process, which may lead to differences between this version and the Version of Record. Please cite this article as doi: $\underline{10.1111 / \text { JOOR.13156 }}$

This article is protected by copyright. All rights reserved 
Hong He, Department of Orthodontics, Hubei-MOST KLOS and KLOBM, School \& Hospital of Stomatology, Wuhan University, Luoyu Road 237, Hongshan District, Wuhan 430079, China (E-mail: drhehong@whu.edu.cn)

\section{Declaration of interest}

None

\section{Funding}

This study has no specific source of financial support

\begin{tabular}{|c|c|}
\hline Author name & Contribution \\
\hline Bushra Sufyan ALmaqrami & $\begin{array}{l}\text { Substantial contributions to the conception and design of the } \\
\text { work; the acquisition, analysis, and interpretation of data; } \\
\text { drafting the manuscript; critical revision of the manuscript for } \\
\text { important intellectual content; and approval of the final version } \\
\text { of the manuscript. }\end{array}$ \\
\hline Maged Sultan Alhammadi & $\begin{array}{l}\text { Substantial contributions to the conception and design of the } \\
\text { work; statistical analysis and interpretation of the data; critical } \\
\text { revision of the manuscript for important intellectual content; and } \\
\text { approval of the final version of the manuscript. }\end{array}$ \\
\hline Bojun Tang & $\begin{array}{l}\text { Substantial contributions to the acquisition of data (sample } \\
\text { recruiting, data collection and clinical examination), and approval } \\
\text { of the final version of the manuscript. }\end{array}$ \\
\hline Enas Senan ALyafrusee & $\begin{array}{l}\text { Statistical analysis and interpretation of the data; Substantial } \\
\text { contributions to the acquisition of data (sample recruiting, data } \\
\text { collection and clinical examination); and approval of the final } \\
\text { version of the manuscript. }\end{array}$ \\
\hline Fang Hua & $\begin{array}{l}\text { Grammatical, typo and intellectual editing of the manuscript; } \\
\text { critical revision of the manuscript for important intellectual } \\
\text { content and approval of the version of the manuscript. }\end{array}$ \\
\hline
\end{tabular}

This article is protected by copyright. All rights reserved 


\begin{tabular}{|l|l|}
\hline Hong He & $\begin{array}{l}\text { Contribution to the design of the work; acquisition, analysis and } \\
\text { interpretation of data; critical revision of the manuscript for } \\
\text { important intellectual content; and approval of the final version } \\
\text { of the manuscript. }\end{array}$ \\
\hline
\end{tabular}

\section{Abstract}

Objectives: The purpose of this study was to three-dimensionally (3D) evaluate the morphological and positional features of the temporomandibular joint (TMJ) in adults with unilateral and bilateral posterior crossbite compared with aligned control subjects.

Materials and Methods: This cross-sectional comparative study analyzed cone beam computed tomography (CBCT) images of 90 adult subjects' divided into three equal groups: bilateral posterior crossbite (BCG), unilateral posterior crossbite (UCG), and control group (CG). 3D measurements of the TMJ included: (1) position, angulation, and inclination of the mandibular condyles; (2) centralization of the condyles in their respective mandibular fossae; and (3) volumetric measurements of the TMJ spaces. Intra- and inter-group differences were identified using the paired Student's $t$-test and an analysis of variance (ANOVA) followed by Tukey's post hoc test, respectively.

Results: Regarding the intra-group side-based comparisons, there were significant differences in the anterior and superior joint spaces and the anteroposterior condylar joint position in the UCG.

Inter-group comparisons revealed significant differences in the vertical condylar inclination, medial condylar position, condylar width and height, and volumetric joint space between the unaffected side of the UCG and left sides of the other groups. There were significant differences in the anteroposterior condylar inclination, medial condylar position, condylar width and height, anterior, 
posterior, superior, and volumetric joint spaces, and anteroposterior condylar joint position between the crossbite side of the UCG and the right sides of the other groups.

Conclusion: Skeletal crossbite accompanied with characteristic morphological and positional TMJ features associated with unilateral posterior crossbite and are associated with side-specific TMJ asymmetry.

Keywords: Temporomandibular joint; Posterior crossbite; Mandibular condyle; Joint spaces; Threedimensional analysis;

\section{Introduction}

A posterior crossbite is a relatively common occlusal problem described as a transverse arch discrepancy (1-3). It is one of the most frequently occurring malocclusions in adolescents with a prevalence ranging from $7 \%$ to $23 \%(4,5)$. Based on a recent systematic review (6), the global prevalence of posterior crossbite is around $9.4 \%$ and $11.7 \%$ in the permanent and mixed dentition stages, respectively. This prevalence ranged from $7.1 \%$ in the American population to $13.1 \%$ in the European population. A posterior crossbite can be caused by a transverse deficiency in the maxilla relative to the mandible, which could or could not be associated with functional mandibular shift to maintain proper occlusal function. This impaired maxillomandibular relationship may have long-term effects on the growth and development of the teeth and their supporting skeletal bases $(7,8)$.

Adolescent and adult patients with transverse malocclusions are at increased risk of developing craniomandibular disorders, showing more signs and symptoms of these problems (9-11). An altered structural relationship between the upper and lower dentitions can result in mandibular shift and postural alterations (12-14) with possible right-to-left-side differences in the condyle-fossa relationship (15).

The impact of posterior crossbite on the morphology of the temporomandibular joint (TMJ) varies from none to major (16-25). There are studies $(16-21,25)$ reporting the uncertainty to the moment of this association, with presence of other contradictory studies $(22-24,26)$. Potential explanations for these contradictory findings include study design, sample size, research approach, imaging technique, 
and whether the assessment was performed in two or three dimensions (2D, 3D); given the anatomical complexity of this region, seemingly innocuous methodological differences can easily produce such disparate outcomes. Furthermore, these studies use subjective scoring systems rather than standardized methods to analyze condylar position, inclination, angulation, and the condyle-fossa relationship.

Among studies on the relationship between posterior crossbite components and TMJ configuration, Nerder et al. (18) suggest that functional imbalances associated with posterior crossbite may change the developmental pattern of the associated skeletal units, causing 3D asymmetry in the position and path of the condyles within the glenoid fossae, which can lead to the permanent structural asymmetry of the mandible. Lam et al.(19) and Hesse et al.(20) concluded that this type of malocclusion causes the condyle to become asymmetrically positioned in the glenoid fossa. Kecik et al. (21) found that the condyles were mispositioned in the glenoid fossa on the crossbite side. Recently Muraglie et al. (25) shown a higher percentage of glenoid fossa and articular eminence asymmetry while comparing the crossbite and non-crossbite sides of posterior unilateral crossbite (PUXB) patients compared to the control sample. In contrast, Leonardi et al. (23) describe symmetric condylar positioning between the crossbite and aligned sides. Pittman et al. (24) found no positional differences in the condyles from control and crossbite groups and suggest that the TMJ-related signs and symptoms may be related to TMJ remodeling instead.

To our knowledge, there has been limited assessment of the morphological and positional characteristics of TMJ in adults with unilateral and bilateral posterior crossbite, using 3D analyses. Hence this study aimed to evaluate in a 3D approach the morphological and positional temporomandibular joint (TMJ) features in adults with unilateral, bilateral posterior crossbite compared with their unaffected peers in Chinese adult population.

\section{Materials and Methods}

\section{Sample selection}

This cross-sectional, comparative study was approved by the Ethics Committee of the Hospital of Stomatology, Wuhan University, Wuhan, China (No. 2020-B41). 
Sample size was determined using an alpha value of 0.05 and a power of $95 \%$ based on the study conducted by Veli et al. (13), in which the mean body volume of the right side of the control group was $20.39 \pm 3.37 \mathrm{~mm}^{3}$ and $15.78 \pm 2.17 \mathrm{~mm}^{3}$ in the same side of the bilateral crossbite group and the mean body length on the right side of the control group was $72.12 \pm 11.83 \mathrm{~mm}$ and $81.46 \pm 4.95 \mathrm{~mm}$ on the crossbite side of the unilateral crossbite group, the resulting sample size was 11 and 26 patients, respectively, which was increased to 30 participants per group.

The following criteria were used to select patients:

Inclusion criteria:

1) Aged 18 - 30 years old.

2) Maxillary transverse deficiency with posterior crossbite involving greater than two teeth distal to the maxillary canine on both sides or on one side only with the teeth at their maximum intercuspal position.

Exclusion criteria:

1) Under 18 years old.

2) Diagnosed with temporomandibular disorders based on recorded clinical data in the patients' dental records; the Diagnostic Criteria for Temporomandibular Disorders (DC/TMD) was used during assessment of the TMD which include the muscular and/or TMJ pain, TMJ sounds and the range of the mandibular motions (27).

3) History of facial or dental trauma.

3) Congenital craniofacial syndrome or anomaly (e.g., cleft lip and/or palate).

4) A history of surgery in the craniofacial region.

5) Condylar imaging evidence of degenerative disease (e.g., erosion, subchondral cyst, condylar hyperplasia).

The skeletal crossbite assessed radiographically using the multiplanar CBCT images by measuring the maxillary basal width (the depth of the concavity of the lateral maxillary contours, at the junction of the maxilla and the zygomatic buttress) and the mandibular width (the most buccal point of the cortical plate on both the right and left sides at the level of the mandibular first molar bifurcation region) as presented in Figure $1(28,29)$.

This article is protected by copyright. All rights reserved 
Demographic, clinical, and CBCT imaging data from 1,756 patients who attended the dental clinic at the Hospital of Stomatology, Wuhan University were considered for inclusion. Subject with unilateral and bilateral crossbite underwent $\mathrm{CBCT}$ imaging for diagnosis and possible orthodontic and/or orthognathic surgery planning purposes, and these were included in their preoperative records. Patients who were imaged mostly due to multiple third molar impactions in both arches were selected to serve as controls. The sample was divided into three equal groups of 30 patients each: (1) Unilateral posterior crossbite group (UCG) - 6 male, 24 female; mean age: $23.27 \pm 3.36$ years; (2) Bilateral posterior crossbite group (BCG) - 8 male, 22 female; mean age: $22.90 \pm 3.89$ years; and (3) Control group (CG) - 7 male, 23 female; mean age: $21.35 \pm 2.79$ years.

\section{CBCT analysis}

CBCT images were acquired using New Tom VGi 9 (Imola, Italy) at the Hospital of Stomatology, Wuhan University using the following acquisition parameters: large field of view $(20 \times 25 \mathrm{~cm}), 110$ $\mathrm{kV}, 8.8 \mathrm{mAs}$, and 18 -second exposure time. The selected voxel dimension was $0.3 \mathrm{~mm}$ and the slice thickness was $2 \mathrm{~mm}$. Frankfort horizontal plane was made parallel to the floor with a crossing laser guide. According to the imaging protocol, the patient was instructed not to swallow or move during the scanning process.

Digital Imaging and Communications in Medicine (DICOM) files of the CBCT images were obtained and then introduced to the Invivo Anatomage 5.4 version (Anatomage, San Jose, CA, USA) for three dimensional and volumetric analysis.

The standardized, stepwise, innovative 3D TMJ analysis designed by Alhammadi et al. (30-32) was applied in this study. To make these analysis reproducible, detailed steps are presented as online (supplementary material 1). The 3D temporomandibular landmarks are presented in Figure 2, and the 2D and 3D planes, skeletal measurements, and comprehensive TMJ measurements are presented in Table 1.

Two different methods were used to determine the condylar position with accuracy and precision. The first method assessed condylar position relative to the craniofacial complex (basal reference 
planes) and the second used the formula proposed by Pullinger and Hollender (PS - AS $/$ PS + AS $\times 100$ ) (33).

The total joint space was determined using the tuberculo-meatal (TM) line from the anterior tubercle (AT) to the inferior auditory meatus (IM). The volumetric joint space (VJS) was calculated using cubic $3 \mathrm{D}$ analysis of the whole area by sectioning the total joint space into six, $1.5-\mathrm{mm}$ wide sections, as represented in Figure 3, and applying the sigma volume equation $\mathrm{v} \cong \sum_{\mathrm{k}}=1 \mathrm{~A}\left(\dot{\mathrm{x}}_{\mathrm{I}}\right) \Delta \mathrm{x}$ (34).

Cases were analyzed twice within a two-week interval by two different observers to ensure the intra- and inter-examiner reliability of the selected measurements.

\section{Statistical Analyses}

Data were analyzed using the Statistical Package for Social Sciences (SPSS) software, version 24 (IBM Corp., Armonk, NY, USA) for Windows. Intraclass correlation coefficients (ICCs) and the absolute and relative technical error of measurement (TEM and rTEM) were calculated to assess the reliability and reproducibility of the measurements. Descriptive statistics, including the mean and standard deviation (SD) of each variable, were calculated and presented as such. Data were checked for normal distribution using the Shapiro-Wilk's test.

Intra-group comparisons between both sides were performed using the paired samples t-test. For inter-group comparisons, one-way analysis of variance (ANOVA) and Tukey's honestly significant difference (HSD) tests were used. A P-value below 0.05 was considered statistically significant.

\section{Results}

Ninety patients fulfilled the inclusion and exclusion criteria (21 males and 69 females) with an average age of $22.27 \pm 3.34$ years. The anteroposterior, vertical and transverse skeletal characteristics and the maxillary and mandibular symmetry of the selected sample are presented in Table 2 which showed matched groups in the anteroposterior and vertical skeletal relation and the skeletal symmetry to rule out the effect of these parameters on the TMJ configuration.

This article is protected by copyright. All rights reserved 
The intra- and inter-examiner reliability analysis data is presented in Table 3. The descriptive statistics and significance values for the left and right TMJ measurements of all groups are presented in Table 4. The UCG showed statistically significant side differences in the anterior joint space (AJS; $p=0.046$ ) and superior joint space (SJS; $p=0.023$ ) where the condyles were more posterior and superior on crossbite side than the unaffected side and in the anteroposterior condylar joint position (APCJP) $(p=0.044)$ where the condyles were more eccentrically located on the crossbite side than the unaffected side.

Intergroup comparisons for the left and right sides are given in Tables 5 and 6, respectively. For the unaffected side of the UCG and the left side of the other groups, one-way ANOVA revealed significant differences in the vertical condylar inclination $(p<0.001)$, medial condylar position $(p<$ $0.001)$, condylar width $(p<0.001)$, condylar height $(p<0.001)$, AJS $(p=0.038)$, and VJS $(p=0.020)$. The vertical condylar inclination was significantly greater in the CG than the UCG and BCG; $(p<$ 0.001). However, the medial condylar position, condylar width, condylar height, and AJS were significantly greater in the CG than the BCG and UCG.

Regarding the crossbite side of the UCG and the right sides of the other groups, statistically significant differences were found in the anteroposterior condylar inclination $(p<0.044)$, medial condylar position $(p<0.001)$, condylar width $(p<0.001)$, condylar height $(p<0.001)$, AJS $(p=$ $0.007)$, posterior joint space (PJS) $(p=0.023)$, SJS $(P=0.023)$, APCJP $(p=0.009)$, and VJS $(p<$ 0.001). The anteroposterior condylar inclination, medial condylar position, condylar width, condylar height, and the anterior, posterior, and superior joint spaces were significantly greater in the CG than the BCG and UCG.

\section{Discussion}

Asymmetrical function in patients with posterior crossbite leads to the differential development of the right and left sides of the mandible over time $(16,18,20,35)$. The abnormal movement of the lower jaw can place strain on the orofacial structures and adversely affect the TMJs and masticatory system (13). Changes in the morphology of the mandibular condyles, articular fossa, and associations with the existing malocclusion have been reported during the primary and mixed dentition stages (16- 
24). Detailed measurements of the TMJ's anatomical structures in 3D planes of space in crossbite occlusions and thorough interpretations provide insight into the pathological effects of untreated crossbite on the TMJ. To the best of our knowledge, this is the first study to evaluate the TMJ structures of adults with variant posterior crossbite relative to their unaffected peers in $3 \mathrm{D}$ using standardized and comprehensive TMJ analysis.

$\mathrm{CBCT}$ is a valuable method for assessing the mandibular condyle and articular fossa as it provides accurate measurement of the inclination, position, and parameters of each component in the three orthogonal planes $(36,37)$. Most studies evaluating the TMJ use 2D (16-21), those that have used 3D to characterize the relationship between an existing malocclusion and the TMJ only evaluate the anterior, posterior, and superior joint spaces of the latter, as well as the anteroposterior condylar inclination using only a single view (axial) of this anatomically complex 3D region $(23,24,38)$. Here we present a detailed, standardized, 3D analysis of the TMJ that was hereto previously undescribed.

In the present study, side comparisons within the UCG group revealed significant differences between the AJS, SJS, and APCJP of the crossbite and aligned sides. In contrast, Leonardi et al. (23) and Pittman et al. (24) found no side-based differences in the AJS and SJS of an adolescent population aged 7.4 to 11.4 years old with functional posterior crossbite. Regarding the APCJP, the joints appeared to be eccentrically located (slightly anterior) on the crossbite side compared to its centralized position on the unaffected side. This result may be explained by previous studies that found asymmetric activity of masticatory muscles and differences in condyle position within the fossa between the crossbite side and non-crossbite side in patients with PUXB $(39,40)$.

Regarding intergroup comparisons, the condylar inclination was significantly different on the crossbite side of the UCG and right side of both the CG and BCG. This is in contrast to studies that found no differences between the CG and $\operatorname{UCG}(23,24)$, potentially due to the more precise localization of the condyle's most lateral and medial points in three planes and the 3D digitization of the MSP landmarks in the present study. The CG also had greater vertical condylar inclination than the crossbite groups.

This article is protected by copyright. All rights reserved 
Because the condylar position is a critical component of the TMJ, it was evaluated using two different methods. The first method showed that the linear measurements of the crossbite and aligned sides in the UCG and the right and left sides in the other groups were not statistically different except the medial condylar position was significantly greater in the CG and BCG and the CG and UCG on both the right and left sides, likely due to the nearly linear differences (condyle width, height, and total volume) between the groups. Muraglie et al. (25) found that a higher percentage of glenoid fossa and articular eminence asymmetry was found while comparing the crossbite and non-crossbite sides of PUXB patients compared to the control sample, with mean percentage differences greater than 11 for each level of tolerance. These findings further corroborate the adaptive nature of the glenoid fossa even in PUXB patients, which is known to occur after changes in the occlusion and positioning of the mandible.

The second method revealed that the joints appeared to be positioned centrally on both sides of the $\mathrm{CG}$ and BCG, which is in agreement with other studies $(41,42)$. This demonstrates the concentric positions of the condyles in typical occlusions. However, in the UCG, the joints appeared to be centralized on the aligned side and eccentric (slightly anterior) on the crossbite side. Recently Leonardi et al. (43) also found statistically significant differences between the two sides of the mandible of the same patients with PUXB in comparison to the control group. Their finding suggested that positional asymmetry produced a mild mandibular regional asymmetry especially affecting the condyle, the mandibular angle, the alveolar processes and the mandibular ramus, their study supports the belief that an untreated unilateral crossbite can lead to skeletal asymmetry of the mandible.

There were non-significant side-based variations in condylar length (mediolateral diameter) and width (anteroposterior diameter) in both crossbite groups (BCG, UCG), as described by Pinto et al. (16), Kiki et al. (17), and Illipronti-Filho et al. (38). These studies also failed to find any statistically significant differences in their investigations of condylar asymmetry when comparing crossbite and aligned sides. Intergroup comparison showed significant differences between both the CG and BCG and between the CG and UCG on both the right and left sides.

Dimensional measurements of the TMJ joint spaces were considered indicative of condyle movement potential (44). The PJS was greater than the AJS in all three groups except the crossbite 
side of the UCG, and the SJS was the largest joint space in all three groups, which is in agreement with Leonardi et al. (23). In the UCG, the AJS was slightly smaller on the non-crossbite side, and the SJS was slightly larger on the non-crossbite side. This is consistent with the non-crossbite-side condyle being forward and inferior within the glenoid fossa as patients shift toward maximum intercuspation, which further supports the findings of Kecik et al.(21).

There were significant differences in the AJS on the left side of the CG and the aligned side of the UCG and the right side of the CG and right side of the BCG. The PJS and SJS were also significantly different on the right side of the CG and crossbite side of the UCG. These results suggest that displacement occurred as the mandible moved along the eminence, which agrees with Hesse et al. (20) and Kecik et al. (21). This is the first report to measure the medial joint space and the total joint space using this sample criteria and methodology.

The VJS also differed significantly between the CG and UCG. Thus, given the wide range in asymmetry between the control and crossbite groups, this clinical variable seems to be accurate and clinically useful for identifying a problematic condition in subjects with malocclusions that present without pain or TMJ dysfunction. Therefore, based on these findings, we recommend that clinicians measure the VJS in this patient population for diagnostic purposes.

Although our study described side asymmetry between the control and crossbite groups, it aligns with previous studies regarding the relationship between the symmetrical condyle glenoid fossa of the crossbite and non-crossbite sides in patients with untreated posterior crossbites, which could be explained by skeletal remodeling of the TMJs and/or variation in the thickness of the articular TMJ disc, as described by Muraglie, Hesse, Bishara, and Wang (20, 25, 45, 46). Those studies suggest that the TMJ disc can adapt to any alteration caused by occlusal changes to the space between the condyle and fossa. Other studies also conclude that the condyles are capable of adaptive growth changes while the facial asymmetry and lower midline deviation toward the crossbite side persist $(45,47,48)$. The linear effect of the difference between position, morphology and function is not reported. Several previous studies reported that even though there are skeletal differences, this could have no functional implications, on the other hand normal TMJ and muscle function is possible with different condylar positions, dimensions etc (49-51).

This article is protected by copyright. All rights reserved 
In addition to its strengths, this study has some limitations. Despite being calculated in advance, the sample size should be larger in future research. To overcome limitations associated with its study design, a prospective study with more detailed clinical TMJ analyses (e.g., biting force and its correlations with morphological and positional TMJ features) is warranted.

\section{Conclusion}

1) There were positional and dimensional asymmetries in the mandibular condyles of the control, unilateral and bilateral posterior crossbite groups.

2) Asymmetric mandibular positioning caused asymmetric condylar joint spaces; the condyle on the aligned side was inferior and anterior to the condyle on the crossbite side.

3) The total joint volume of the unilateral posterior crossbite group was significantly less than the control group.

\section{Figure Captions:}

Fig. 1 Radiographic assessment of maxillary and mandibular width; A) Axial view of the maxillary arch width reference points; B) Axial view of the mandibular arch width reference points; C) Coronal view of the maxillary and mandibular arch width dimension.

Fig. 2 Sagittal view of TMJ reference points (Detailed description and identification of each reference point presented as online supplementary material)

Fig. 3 Three-dimensional volumetric total joint-space with 2D identification points

\section{Data availability statement:}

The data that support the findings of this study are available from the corresponding author upon reasonable request. 


\section{References}

1. Halicioğlu K, Kiki A, Yavuz I. Maxillary expansion with the memory screw: a preliminary investigation. Korean journal of orthodontics. 2012;42(2):73-9.

2. Kennedy DB, Osepchook M. Unilateral posterior crossbite with mandibular shift: a review. Journal. 2005;71(8):569-73.

3. Sandikçiolu M, Hazar SJAJoO, Orthopedics D. Skeletal and dental changes after maxillary expansion in the mixed dentition. 1997;111(3):321-7.

4. Thilander B, Wahlund S, Lennartsson B. The effect of early interceptive treatment in children with posterior cross-bite. European journal of orthodontics. 1984;6(1):25-34.

5. Thilander B, Lennartsson B. A study of children with unilateral posterior crossbite, treated and untreated, in the deciduous dentition--occlusal and skeletal characteristics of significance in predicting the long-term outcome. Journal of orofacial orthopedics = Fortschritte der Kieferorthopadie : Organ/official journal Deutsche Gesellschaft fur Kieferorthopadie. 2002;63(5):371-83.

6. Alhammadi MS, Halboub E, Fayed MS, Labib A, El-Saaidi C. Global distribution of malocclusion traits: A systematic review. Dental press journal of orthodontics. 2018;23(6):40. e1-. e10.

7. Proffit W, Fields 3rd H. Contemporary orthodontics 3rd ed. St Louis: CV Mosby. 2000:185-95.

8. McNamara JA, Jr. Early intervention in the transverse dimension: is it worth the effort? American journal of orthodontics and dentofacial orthopedics : official publication of the American Association of Orthodontists, its constituent societies, and the American Board of Orthodontics. 2002;121(6):572-4.

9. Egermark-Eriksson I, Carlsson GE, Magnusson T, Thilander B. A longitudinal study on malocclusion in relation to signs and symptoms of cranio-mandibular disorders in children and adolescents. European journal of orthodontics. 1990;12(4):399-407.

10. Mohlin BO, Derweduwen K, Pilley R, Kingdon A, Shaw W, Kenealy P. Malocclusion and temporomandibular disorder: a comparison of adolescents with moderate to severe dysfunction with those without signs and symptoms of temporomandibular disorder and their further development to 30 years of age. The Angle Orthodontist. 2004;74(3):319-27.

11. McNamara Jr JA, Seligman DA, Okeson JPJJoop. Occlusion, orthodontic treatment, and temporomandibular disorders: a review. 1995;9(1):73-90.

This article is protected by copyright. All rights reserved 
12. Castelo P, Pereira L, Andrade A, Marquezin M, Gavião M. Evaluation of facial asymmetry and masticatory muscle thickness in children with normal occlusion and functional posterior crossbite. Minerva stomatologica. 2010;59(7-8):423-30.

13. Veli I, Uysal T, Ozer T, Ucar FI, Eruz M. Mandibular asymmetry in unilateral and bilateral posterior crossbite patients using cone-beam computed tomography. The Angle Orthodontist. 2011;81(6):966-74.

14. Agostino P, Ugolini A, Signori A, Silvestrini-Biavati A, Harrison JE, Riley P. Orthodontic treatment for posterior crossbites. The Cochrane database of systematic reviews. 2014(8):Cd000979.

15. Takada J-i, Miyamoto JJ, Yokota T, Ono T, Moriyama K. Comparison of the mandibular hinge axis in adult patients with facial asymmetry with and without posterior unilateral crossbite. European journal of orthodontics. 2015;37(1):22-7.

16. Pinto AS, Buschang PH, Throckmorton GS, Chen P. Morphological and positional asymmetries of young children with functional unilateral posterior crossbite. American Journal of Orthodontics and Dentofacial Orthopedics. 2001;120(5):513-20.

17. Kiki A, Kılıç N, Oktay H. Condylar asymmetry in bilateral posterior crossbite patients. The Angle orthodontist. $2007 ; 77(1): 77-81$.

18. Nerder $\mathrm{PH}$, Bekke $\mathrm{M}$, Solow $\mathrm{B}$. The functional shift of the mandible in unilateral posterior crossbite and the adaptation of the temporomandibular joints: a pilot study. The European Journal of Orthodontics. 1999;21(2):155-66.

19. Lam PH, Sadowsky C, Omerza F. Mandibular asymmetry and condylar position in children with unilateral posterior crossbite. American Journal of Orthodontics and Dentofacial Orthopedics. 1999;115(5):569-75.

20. Hesse KL, Årtun J, Joondeph DR, Kennedy DB. Changes in condylar position and occlusion associated with maxillary expansion for correction of functional unilateral posterior crossbite. American Journal of Orthodontics and Dentofacial Orthopedics. 1997;111(4):410-8.

21. Kecik D, Kocadereli I, Saatci I. Evaluation of the treatment changes of functional posterior crossbite in the mixed dentition. American Journal of Orthodontics and Dentofacial Orthopedics. 2007;131(2):202-15.

22. Tecco S, Saccucci M, Nucera R, Polimeni A, Pagnoni M, Cordasco G, et al. Condylar volume and surface in Caucasian young adult subjects. BMC medical imaging. 2010;10(1):28.

This article is protected by copyright. All rights reserved 
23. Leonardi R, Caltabiano M, Cavallini C, Sicurezza E, Barbato E, Spampinato C, et al. Condyle fossa relationship associated with functional posterior crossbite, before and after rapid maxillary expansion. The Angle Orthodontist. 2012;82(6):1040-6.

24. Pittman L, Shipley TS, Martin CA, Xiang J, Ngan PW, editors. CBCT evaluation of condylar changes in children with unilateral posterior crossbites and a functional shift. Seminars in Orthodontics; 2019: Elsevier. 25. Muraglie S, Leonardi R, Aboulazm K, Stumpo C, Loreto C, Grippaudo CJTAO. Evaluation of structural skeletal asymmetry of the glenoid fossa in adult patients with unilateral posterior crossbite using surface-tosurface matching on CBCT images. 2020;90(3):376-82.

26. Farella M, Michelotti A, lodice G, Milani S, Martina RJJodr. Unilateral posterior crossbite is not associated with TMJ clicking in young adolescents. 2007;86(2):137-41.

27. Schiffman E, Ohrbach R, Truelove E, Look J, Anderson G, Goulet J-P, et al. Diagnostic criteria for temporomandibular disorders (DC/TMD) for clinical and research applications: recommendations of the International RDC/TMD Consortium Network and Orofacial Pain Special Interest Group. 2014;28(1):6.

28. Simontacchi-Gbologah MS TR, Boucher NS, Vanarsdall RL, Secchi AG. Comparison of Three Methods to Analyze the Skeletal Transverse Dimension in Orthodontic Diagnosis [thesis]. University of Pennsylvania. 2010.

29. Shah SR, Fishel D, Tamburrino R. PERIODONTAL RATIONALE FOR TRANSVERSE SKELETAL NORMALIZATION. orthod pract. 2014;5(3):50-3.

30. Alhammadi MS, Fayed MS, Labib A. Three-dimensional assessment of temporomandibular joints in skeletal Class I, Class II, and Class III malocclusions: cone beam computed tomography analysis. Journal of the World Federation of Orthodontists. 2016;5(3):80-6.

31. Elfeky HY, Fayed MS, Alhammadi MS, Soliman SAZ, El Boghdadi DM. Three-dimensional skeletal, dentoalveolar and temporomandibular joint changes produced by Twin Block functional appliance. Journal of Orofacial Orthopedics/Fortschritte der Kieferorthopädie. 2018;79(4):245-58.

32. Alhammadi M, Fayed M, Labib A. Three - dimensional assessment of condylar position and joint spaces after maxillary first premolar extraction in skeletal Class II malocclusion. Orthodontics \& Craniofacial Research. 2017;20(2):71-8.

33. Pullinger A, Hollender L. Variation in condyle-fossa relationships according to different methods of evaluation in tomograms. Oral surgery, oral medicine, oral pathology. 1986;62(6):719-27.

This article is protected by copyright. All rights reserved 
34. Abdulqader AA, Ren L, Alhammadi M, Abdu ZA, Mohamed AAS. Three-dimensional analysis of temporomandibular joint in Chinese adults with normal occlusion and harmonious skeleton. Oral Radiology. 2019:1-12.

35. Uysal T, Sisman Y, Kurt G, Ramoglu SI. Condylar and ramal vertical asymmetry in unilateral and bilateral posterior crossbite patients and a normal occlusion sample. American journal of orthodontics and dentofacial orthopedics. 2009;136(1):37-43.

36. Seth V, Kamath $\mathrm{P}$, Venkatesh $\mathrm{M}$, Prasad R. Cone beam computed tomography: third eye in diagnosis and treatment planning. Virtual Journal of Orthodontics. 2011;9(1).

37. Ribeiro ANC, De Paiva JB, Rino-Neto J, Illipronti-Filho E, Trivino T, Fantini SM. Upper airway expansion after rapid maxillary expansion evaluated with cone beam computed tomography. The Angle Orthodontist. 2012;82(3):458-63.

38. Illipronti-Filho E, FANTINI SM, Chilvarquer I. Evaluation of mandibular condyles in children with unilateral posterior crossbite. Brazilian oral research. 2015;29(1):1-7.

39. Tsanidis N, Antonarakis G, Kiliaridis SJJoOR. Functional changes after early treatment of unilateral posterior cross - bite associated with mandibular shift: a systematic review. 2016;43(1):59-68.

40. Rodrigues L, Traina AA, Nakamai LF, Luz JGdCJBor. Effects of the unilateral removal and dissection of the masseter muscle on the facial growth of young rats. 2009;23(1):89-95.

41. Vitral RWF, da Silva Campos MJ, Rodrigues AF, Fraga MR. Temporomandibular joint and normal occlusion: Is there anything singular about it? A computed tomographic evaluation. American journal of orthodontics and dentofacial orthopedics. 2011;140(1):18-24.

42. Alhammadi MS, Shafey AS, Fayed MS, Mostafa YA. Temporomandibular joint measurements in normal occlusion: a three-dimensional cone beam computed tomography analysis. Journal of the World Federation of Orthodontists. 2014;3(4):155-62.

43. Leonardi R, Muraglie S, Bennici O, Cavallini C, Spampinato CJTAO. Three-dimensional analysis of mandibular functional units in adult patients with unilateral posterior crossbite: A cone beam study with the use of mirroring and surface-to-surface matching techniques. 2019;89(4):590-6.

44. HOLEN GALEKOVIĆ N, Fugošić V, Braut V, Ćelić R. Influence of the hinge axis transfer modality on the three-dimensional condylar shift between the centric relation and the maximum intercuspation positions. Acta stomatologica Croatica. 2015;49(1):36-44.

This article is protected by copyright. All rights reserved 
45. Bishara SE, Burkey PS, Kharouf JG. Dental and facial asymmetries: a review. The Angle Orthodontist. 1994;64(2):89-98.

46. Wang M-Q, He J-J, Li G, Widmalm SE. The effect of physiological nonbalanced occlusion on the thickness of the temporomandibular joint disc: a pilot autopsy study. The Journal of prosthetic dentistry. 2008;99(2):148-52.

47. O'Byrn BL, Sadowsky C, Schneider B, BeGole EA. An evaluation of mandibular asymmetry in adults with unilateral posterior crossbite. American Journal of Orthodontics and Dentofacial Orthopedics. 1995;107(4):394-400.

48. Myers DR, Barenie JT, Bell RA, Williamson EH. Condylar position in children with functional posterior crossbites: before and after crossbite correction. Pediatric dentistry. 1980;2(3):190-4.

49. Leonardi R, Caltabiano M, Cavallini C, Sicurezza E, Barbato E, Spampinato C, et al. Condyle fossa relationship associated with functional posterior crossbite, before and after rapid maxillary expansion. 2012;82(6):1040-6.

50. Merigue LF, Conti AC, Oltramari-Navarro PV, Navarro Rde L, Almeida MR. Tomographic evaluation of the temporomandibular joint in malocclusion subjects: condylar morphology and position. Brazilian oral research. 2016;30.

51. Rodrigues AF, Fraga MR, Vitral RWFJAjoo, orthopedics d. Computed tomography evaluation of the temporomandibular joint in Class I malocclusion patients: condylar symmetry and condyle-fossa relationship. 2009;136(2):192-8.

This article is protected by copyright. All rights reserved 
Table 1 Skeletal reference planes and measurements used in the study

\begin{tabular}{|c|c|c|}
\hline \multicolumn{3}{|c|}{ 3D reference planes } \\
\hline HP & Horizontal plane & Constructed by three-point right Orbital with two sides porion \\
\hline MSP & Midsagittal Plane & Constructed by three-point N, BA, and IF \\
\hline VP & Vertical Plane & Constructed Sella point and perpendicular on sagittal and horizontal plane \\
\hline \multicolumn{3}{|c|}{ 3D Measurements } \\
\hline \multicolumn{3}{|c|}{ Skeletal measurements } \\
\hline SNA & Maxillary anteroposterior position & The angle between 3-point landmarks Sella, nasion and A points \\
\hline SNB & Mandibular anteroposterior position & The angle between 3-point landmarks Sella, nasion and B points \\
\hline ANB & Skeletal anteroposterior Jaw relation & The angle from $\mathrm{A}$ point, $\mathrm{N}$ point, $\mathrm{B}$ point \\
\hline MP/SN & Skeletal vertical Jaw relation & The angle between Sella-Nasion (SN) and Go- Me (MP) \\
\hline Mx-Md Diff & $\begin{array}{c}\text { Maxillo-Mandibular transverse } \\
\text { difference }\end{array}$ & The difference between maxillary and mandibular transverse width \\
\hline ANS-MSP & Maxillary Symmetry & The linear distance measured between anterior nasal spine point and MSP \\
\hline Me-MSP & Mandibular Symmetry & The linear distance measured between menton point and MSP \\
\hline \multicolumn{3}{|c|}{ Mandibular fossa dimension } \\
\hline $\mathrm{MFH}$ & Mandibular fossa height & Distance extend perpendicularly from bony MF to TM line \\
\hline MFW & Mandibular fossa width & Distance extend horizontally from AF to PF \\
\hline \multicolumn{3}{|c|}{ Condylar inclination } \\
\hline MCI & Mediolateral & Angle of ACP-PCP line with HP \\
\hline VCI & Vertical & Angle of MCP-LCP line with VP plane \\
\hline APCI & Anteroposterior & Angle of MCP-LCP line with MSP \\
\hline \multicolumn{3}{|c|}{ Condylar position } \\
\hline VCP & Vertical & Distance extends vertically from SCP to HP \\
\hline APCP & Anteroposterior & Distance extends anteroposterior from ACP to VP \\
\hline MCP & Mediolateral & Distance extends mediolaterally from ACP to MSP \\
\hline
\end{tabular}

This article is protected by copyright. All rights reserved 


\begin{tabular}{|c|c|c|}
\hline CL & Condylar length & The distance between MCP and LCP \\
\hline CW & Condylar width & The condyle width between CWa - CWp \\
\hline CH & Condylar height & The perpendicular distance between SCP \&CNA line (ANP-PNP) \\
\hline TM Joint spaces & \multicolumn{2}{|c|}{} \\
\hline AJS & Anterior Joint Space & Closest distance between AJSC-AJSF \\
\hline PJS & Posterior joint space & Closest distance between PJSC-PJSF \\
\hline AJS & Superior joint space & Medial joint space Closest distance between MCP-MJFS \\
\hline MJS & Medial joint space & The difference between condyle height to TM line and condyle height \\
to the condyle neckline
\end{tabular}

This article is protected by copyright. All rights reserved 
Table 2 Three dimensional skeletal measurements of the study sample

\begin{tabular}{|c|c|c|c|c|c|c|c|c|c|}
\hline \multirow{2}{*}{ variables } & \multicolumn{3}{|c|}{ Study group † } & \multicolumn{3}{|c|}{ Control group } & \multicolumn{3}{|c|}{ Study VS Control (P value $)^{\dagger}$} \\
\hline & $\begin{array}{l}\text { Class I } \\
(n=28)\end{array}$ & $\begin{array}{l}\text { Class II } \\
(\mathbf{n}=\mathbf{2 0})\end{array}$ & $\begin{array}{c}\text { Class III } \\
(n=12)\end{array}$ & $\begin{array}{l}\text { Class I } \\
(n=12)\end{array}$ & $\begin{array}{l}\text { Class II } \\
(n=10)\end{array}$ & $\begin{array}{c}\text { Class III } \\
(n=8)\end{array}$ & $\begin{array}{c}\text { Class } \\
\text { I }\end{array}$ & $\begin{array}{c}\text { Class } \\
\text { II }\end{array}$ & Class III \\
\hline SNA $\left(^{\circ}\right)$ & $81.6 \pm 3.8$ & $81.1 \pm 3.2$ & $80.6 \pm 3.5$ & $82.8 \pm 3.4$ & $80.2 \pm 2.8$ & $82.3 \pm 2.5$ & 0.662 & 0.240 & 0.065 \\
\hline SNB $\left(^{\circ}\right)$ & $79.4 \pm 4.2$ & $76.5 \pm 3.2$ & $80.99 \pm 3.4$ & $80.9 \pm 3.5$ & $75.6 \pm 2.7$ & $82.9 \pm 2.5$ & 0.695 & 0.316 & 0.055 \\
\hline $\mathrm{ANB}\left(^{\circ}\right)$ & $2.14 \pm 2.0$ & $4.6 \pm 0.4$ & $-0.4 \pm 0.2$ & $1.9 \pm 0.6$ & $4.6 \pm 0.3$ & $-0.6 \pm 0.2$ & 0.665 & 0.454 & 0.303 \\
\hline MP/SN $\left(^{\circ}\right)$ & $36.4 \pm 5.4$ & $38.5 \pm 3.5$ & $34.8 \pm 4.9$ & $35.1 \pm 7.1$ & $35.2 \pm 4.6$ & $34.1 \pm 5.1$ & 0.841 & 0.093 & 0.552 \\
\hline $\begin{array}{l}\text { Maxillo-Mandibular } \\
\text { transverse difference }\end{array}$ & $0.2 \pm 1.4$ & $\begin{array}{c}-0.6 \pm \\
1.0\end{array}$ & $0.9 \pm 1.6$ & $5.7 \pm 0.9$ & $5.7 \pm 0.9$ & $5.2 \pm 0.8$ & 0.000 & 0.000 & 0.000 \\
\hline Me-MSP (mm) & $1.87 \pm 0.7$ & $2.2 \pm 0.9$ & $1.5 \pm 0.9$ & $2.40 \pm 0.54$ & $1.9 \pm 1.0$ & $1.8 \pm 0.9$ & 0.093 & 0.158 & 0.938 \\
\hline ANS-MSP (mm) & $1.0 \pm 1.13$ & $1.1 \pm 0.7$ & $0.8 \pm 0.6$ & $1.3 \pm 0.9$ & $1.2 \pm 0.5$ & $1.0 \pm 0.7$ & 0.749 & 0.437 & 0.432 \\
\hline
\end{tabular}

¡: Unilateral and Bilateral crossbite subjects have been unified in the "sample Group"

${ }^{\dagger}$ : paired t-test/ Wilcoxon signed- rank test $* \mathrm{P}<0.05$

This article is protected by copyright. All rights reserved 
Table 3 Reliability analysis of the three-dimensional measurements used in the study

\begin{tabular}{|c|c|c|c|c|c|c|c|c|}
\hline \multirow{2}{*}{ Variable } & \multicolumn{4}{|c|}{ Intra-examiner reliability } & \multicolumn{4}{|c|}{ Inter-examiner reliability } \\
\hline & ICC & TEM & rTEM & $\mathrm{R}$ & ICC & TEM & rTEM & $\mathrm{R}$ \\
\hline MLCI & 0.986 & 0.48 & 5.77 & 0.986 & 0.984 & 0.47 & 4.85 & 0.983 \\
\hline VCI & 0.989 & 1.04 & 1.7 & 0.988 & 0.989 & 1.03 & 1.71 & 0.988 \\
\hline APCI & 0.989 & 01.03 & 1.71 & 0.988 & 0.983 & 1.29 & 2.13 & 0.982 \\
\hline VCP & 0.977 & 0.03 & 16.29 & 0.976 & 0.967 & 0.364 & 16.31 & 0.966 \\
\hline APCP & 0.986 & 0.30 & 4.20 & 0.985 & 0.984 & 0.32 & 4.40 & 0.984 \\
\hline MLCP & 0.964 & 0.47 & 0.90 & 0.964 & 0.958 & 0.49 & 0.95 & 0.951 \\
\hline $\mathbf{C L}$ & 0.976 & 0.43 & 2.43 & 0.976 & 0.973 & 0.46 & 2.60 & 0.973 \\
\hline CW & 0.956 & 0.24 & 3.67 & 0.956 & 0.951 & 0.25 & 3.81 & 0.957 \\
\hline CH & 0.961 & 0.34 & 3.10 & 0.961 & 0.959 & 0.36 & 3.24 & 0.958 \\
\hline AJS & 0.990 & 0.06 & 2.80 & 0.990 & 0.987 & 0.06 & 3.08 & 0.987 \\
\hline PJS & 0.992 & 0.06 & 2.37 & 0.992 & 0.989 & 0.07 & 2.84 & 0.989 \\
\hline SJS & 0.962 & 0.18 & 6.07 & 0.961 & 0.960 & 0.19 & 6.32 & 0.960 \\
\hline MJS & 0.965 & 0.15 & 4.99 & 0.964 & 0.958 & 0.17 & 5.45 & 0.957 \\
\hline MFH & 0.968 & 0.23 & 2.44 & 0.968 & 0.962 & 0.24 & 2.58 & 0.962 \\
\hline MFW & 0.965 & 0.35 & 2.12 & 0.965 & 0.956 & 0.40 & 2.37 & 0.956 \\
\hline VCJP & 0.987 & 0.22 & 3.97 & 0.987 & 0.986 & 0.24 & 4.17 & 0.985 \\
\hline APCJP & 0.994 & 1.23 & 15.0 & 0.994 & 0.991 & 1.48 & 18.1 & 0.991 \\
\hline VOLUME & 0.980 & 6.92 & 2.55 & 0.980 & 0.980 & 6.92 & 2.55 & .0980 \\
\hline
\end{tabular}

ICC intraclass correlation coefficients, TEM and rTEM absolute and relative technical error of measurement 
Table 4 The descriptive statistics and (P) values of paired t-test for the temporomandibular joint measurements of the right and left sides in all studied groups

This article is protected by copyright. All rights reserved 


\begin{tabular}{|c|c|c|c|c|c|c|c|c|c|c|c|c|c|c|c|}
\hline \multirow{3}{*}{ Measurements } & \multicolumn{5}{|c|}{ Normal } & \multicolumn{5}{|c|}{ Unilateral crossbite } & \multicolumn{5}{|c|}{ Bilateral crossbite } \\
\hline & \multicolumn{2}{|c|}{ Left side } & \multicolumn{2}{|c|}{ Right side } & \multirow[b]{2}{*}{$\begin{array}{c}\mathbf{P} \\
\text { value }^{\dagger}\end{array}$} & \multicolumn{2}{|c|}{ Crossbite side } & \multicolumn{2}{|c|}{ Normal side } & \multirow[b]{2}{*}{ P value ${ }^{\dagger}$} & \multicolumn{2}{|c|}{ Left side } & \multicolumn{2}{|c|}{ Right side } & \multirow{2}{*}{$\begin{array}{c}\mathbf{P} \\
\text { value }^{\dagger}\end{array}$} \\
\hline & Mean & SD & Mean & SD & & Mean & SD & Mean & SD & & Mean & SD & Mean & SD & \\
\hline \multicolumn{16}{|c|}{ Mandibular fossa parameters } \\
\hline $\begin{array}{c}\text { Mandibular fossa height } \\
(\mathrm{mm})\end{array}$ & 9.78 & 1.26 & 9.63 & 1.69 & 0.643 & 9.56 & 1.12 & 9.39 & 1.37 & 0.412 & 9.47 & 1.37 & 9.43 & 1.14 & 0.819 \\
\hline $\begin{array}{l}\text { Mandibular fossa width } \\
\text { (mm) }\end{array}$ & 16.50 & 2.50 & 16.3 & 2.55 & 0.656 & 16.17 & 1.90 & 16.67 & 2.15 & 0.108 & 16.94 & 2.20 & 16.48 & 1.86 & 0.055 \\
\hline \multicolumn{16}{|c|}{ Condylar parameters } \\
\hline \multicolumn{16}{|c|}{ Condylar inclination } \\
\hline Mediolateral $\left(^{\circ}\right)$ & 12.98 & 4.61 & 12.4 & 5.39 & 0.652 & 10.55 & 7.39 & 12.75 & 7.23 & 0.083 & 9.89 & 5.34 & 9.24 & 6.30 & 0.425 \\
\hline Vertical $\left(^{\circ}\right)$ & 50.79 & 9.49 & 52.6 & 11.57 & 0.426 & 58.10 & 9.51 & 55.89 & 10.10 & 0.284 & 59.91 & 8.04 & 58.59 & 9.18 & 0.290 \\
\hline Anteroposterior $\left(^{\circ}\right)$ & 70.47 & 8.25 & 72.3 & 6.57 & 0.079 & 68.15 & 6.43 & 68.66 & 6.99 & 0.737 & 70.44 & 7.15 & 70.10 & 6.16 & 0.791 \\
\hline \multicolumn{16}{|c|}{ Condylar position } \\
\hline Vertical (mm) & 1.96 & 1.33 & 2.07 & 1.30 & 0.725 & 1.79 & 1.00 & 1.86 & 1.22 & 0.731 & 1.95 & 1.31 & 1.59 & 1.11 & 0.115 \\
\hline Anteroposterior (mm) & 6.10 & 3.23 & 6.47 & 3.13 & 0.513 & 6.60 & 4.17 & 7.44 & 3.61 & 0.397 & 7.04 & 3.18 & 7.16 & 2.27 & 0.855 \\
\hline Mediolateral (mm) & 57.25 & 4.89 & 57.5 & 5.85 & 0.771 & 50.89 & 2.52 & 50.18 & 2.09 & 0.198 & 50.92 & 2.70 & 51.48 & 2.15 & 0.162 \\
\hline $\begin{array}{l}\text { Vertical condylar joint } \\
\text { position (mm) }\end{array}$ & 5.83 & 2.52 & 6.11 & 2.07 & 0.510 & 16.67 & 2.15 & 5.85 & 1.86 & 0.723 & 5.14 & 1.84 & 5.40 & 1.58 & 0.361 \\
\hline $\begin{array}{c}\text { AP condylar joint position } \\
(\%)\end{array}$ & 0.958 & 18.11 & -2.51 & 14.75 & 0.592 & -5.07 & 21.80 & 2.46 & 17.21 & $0.044 *$ & 6.32 & 19.97 & 8.53 & 15.66 & 0.509 \\
\hline \multicolumn{16}{|c|}{ Condylar dimension } \\
\hline Condylar length (mm) & 18.36 & 2.18 & 18.38 & 1.95 & 0.932 & 17.86 & 3.036 & 18.37 & 2.79 & 0.110 & 18.24 & 2.11 & 17.91 & 2.52 & 0.165 \\
\hline Condylar width (mm) & 8.08 & 1.11 & 8.15 & 0.99 & 0.739 & 7.09 & 1.04 & 7.24 & 1.04 & 0.382 & 6.88 & 1.36 & 6.65 & 1.06 & 0.152 \\
\hline Condylar height (mm) & 13.32 & 2.12 & 13.55 & 2.44 & 0.595 & 11.21 & 1.66 & 11.06 & 1.28 & 0.585 & 10.68 & 1.05 & 10.73 & .92 & 0.784 \\
\hline \multicolumn{16}{|c|}{ TM Joint spaces } \\
\hline Anterior Joint Space (mm) & 2.55 & 0.59 & 2.68 & 0.63 & 0.155 & 2.47 & 0.84 & 2.16 & 0.51 & $0.046^{*}$ & 2.26 & 0.67 & 2.13 & 0.43 & 0.195 \\
\hline $\begin{array}{l}\text { This article is proted } \\
\text { Posterior joint space }(\mathbf{m m})\end{array}$ & $d b y c$ & Aviol & t. All & & 0.742 & 2.22 & 0.71 & 2.28 & 0.56 & 0.607 & 2.59 & 0.76 & 2.59 & 0.71 & 1.000 \\
\hline
\end{tabular}




\begin{tabular}{|c|c|c|c|c|c|c|c|c|c|c|c|c|c|c|c|}
\hline Superior joint space $(\mathrm{mm})$ & 3.47 & 0.86 & 3.37 & 0.85 & 0.506 & 2.87 & 0.74 & 3.20 & 0.84 & $0.023 *$ & 3.04 & 0.72 & 2.91 & .728 & 0.422 \\
\hline Medial joint space $(\mathrm{mm})$ & 2.62 & 0.76 & 2.69 & 0.86 & 0.625 & 2.89 & 1.01 & 2.77 & 0.83 & 0.576 & 3.06 & 0.63 & 3.00 & .71 & 0.593 \\
\hline Whole joint space $\left(\mathrm{mm}^{3}\right)$ & 314.23 & 42.25 & 318.9 & 37.34 & 0.347 & 266.48 & 46.27 & 278.13 & 58.33 & 0.181 & 311.46 & 61.10 & 309.14 & 61.43 & 0.708 \\
\hline
\end{tabular}

$\dagger$ : paired t-test, SD indicates standard deviation, $* \mathrm{P}<.05$

This article is protected by copyright. All rights reserved 
Table 5 The descriptive statistics and significant (P) values of Analysis of variance (ANOVA) and Tukey tests for the temporomandibular joint measurements for the left sides and Non-crossbite side in all studied groups

\begin{tabular}{|c|c|c|c|c|c|c|c|c|c|c|}
\hline \multirow[t]{2}{*}{ Measurements } & \multicolumn{2}{|c|}{ Normal Group (CG) } & \multicolumn{2}{|c|}{$\begin{array}{l}\text { Unilateral Group } \\
\text { (BCG) }\end{array}$} & \multicolumn{2}{|c|}{$\begin{array}{c}\text { Bilateral Group } \\
\text { (UCG) }\end{array}$} & \multirow[t]{2}{*}{ ANOVA } & \multicolumn{3}{|c|}{$\begin{array}{c}\text { Multiple Comparison Tukey HSD } \\
\text { test (P Value) }\end{array}$} \\
\hline & Mean & SD & Mean & SD & Mean & SD & & CG-UCG & CG-BCG & BCG-UCG \\
\hline \multicolumn{11}{|c|}{ Mandibular fossa parameters } \\
\hline Mandibular fossa height (mm) & 9.78 & 1.26 & 9.39 & 1.37 & 3.06 & 0.63 & 0.491 & 0.490 & 0.630 & 0.974 \\
\hline Mandibular fossa width (mm) & 16.50 & 2.50 & 16.67 & 2.15 & 9.47 & 1.37 & 0.754 & 0.957 & 0.750 & 0.879 \\
\hline \multicolumn{11}{|c|}{ Condylar parameters } \\
\hline \multicolumn{11}{|c|}{ Condylar inclination } \\
\hline Mediolateral $\left({ }^{\circ}\right)$ & 12.98 & 4.61 & 12.75 & 7.23 & 9.89 & 5.34 & 0.079 & 0.988 & 0.051 & 0.199 \\
\hline Vertical $\left({ }^{\circ}\right)$ & 50.79 & 9.49 & 55.89 & 10.10 & 59.91 & 8.04 & $0.001 * *$ & 0.117 & 0.001 & 0.213 \\
\hline Anteroposterior $\left({ }^{\circ}\right)$ & 70.47 & 8.25 & 68.66 & 6.99 & 70.44 & 7.15 & 0.565 & 0.633 & 1.000 & 0.595 \\
\hline \multicolumn{11}{|c|}{ Condylar position } \\
\hline Vertical (mm) & 1.96 & 1.33 & 1.86 & 1.22 & 1.95 & 1.31 & 0.953 & 0.956 & 0.999 & 0.965 \\
\hline Anteroposterior (mm) & 6.10 & 3.23 & 7.44 & 3.61 & 7.04 & 3.18 & 0.290 & 0.296 & 0.499 & 0.894 \\
\hline Mediolateral (mm) & 57.25 & 4.89 & 50.18 & 2.09 & 50.92 & 2.70 & $0.000 * * *$ & 0.000 & 0.000 & 0.471 \\
\hline $\begin{array}{l}\text { Vertical condylar joint } \\
\text { position (mm) }\end{array}$ & 5.83 & 2.52 & 5.85 & 1.86 & 16.94 & 2.20 & 0.330 & 0.999 & 0.448 & 0.304 \\
\hline $\begin{array}{c}\text { AP condylar joint position } \\
(\%)\end{array}$ & -0.95 & 18.11 & 2.46 & 17.21 & 5.14 & 1.84 & 0.316 & 0.735 & 0.308 & 0.703 \\
\hline \multicolumn{11}{|c|}{ Condylar dimension } \\
\hline Condylar length (mm) & 18.36 & 2.18 & 18.37 & 2.79 & 18.24 & 2.11 & 0.974 & 1.000 & 0.976 & 0.978 \\
\hline Condylar width $(\mathrm{mm})$ & 8.08 & 1.11 & 7.24 & 1.04 & 6.88 & 1.36 & $0.001 * *$ & 0.012 & 0.001 & 0.489 \\
\hline Condylar height (mm) & 13.32 & 2.12 & 11.06 & 1.28 & 10.68 & 1.05 & $.000 * * *$ & 0.000 & 0.000 & 0.420 \\
\hline
\end{tabular}

This article is protected by copyright. All rights reserved 


\begin{tabular}{|c|c|c|c|c|c|c|c|c|c|c|}
\hline Anterior Joint Space (mm) & 2.55 & 0.59 & 2.16 & 0.51 & 2.26 & 0.67 & $0.038^{*}$ & 0.025 & 0.190 & 0.810 \\
\hline Posterior joint space (mm) & 2.65 & 0.66 & 2.28 & 0.56 & 2.59 & 0.76 & 0.079 & 0.065 & 0.951 & 0.181 \\
\hline Superior joint space (mm) & 3.47 & 0.86 & 3.20 & 0.84 & 3.04 & 0.72 & 0.124 & 0.458 & 0.099 & 0.694 \\
\hline Medial joint space (mm) & 2.62 & 0.76 & 2.77 & 0.83 & 3.04 & 0.72 & 0.067 & 0.735 & 0.043 & 0.280 \\
\hline Whole joint space (mm $\left.\mathbf{m m}^{\mathbf{3}}\right)$ & 314.23 & 42.25 & 278.13 & 58.33 & 6.32 & 19.97 & $0.020^{*}$ & 0.022 & 0.977 & 0.087 \\
\hline
\end{tabular}

SD indicates standard deviation; ANOVA, analysis of variance.

$* \mathrm{P}<.05 ; * * \mathrm{P}<.01 ; * * * \mathrm{P}<.001$

This article is protected by copyright. All rights reserved 
Table 6 The descriptive statistics and significant (P) values of Analysis of variance (ANOVA) and Tukey tests for the temporomandibular joint measurements for the right sides and crossbite side in all studied groups

\begin{tabular}{|c|c|c|c|c|c|c|c|c|c|c|}
\hline \multirow[t]{2}{*}{ Measurements } & \multicolumn{2}{|c|}{ Normal Group (CG) } & \multicolumn{2}{|c|}{$\begin{array}{l}\text { Unilateral Group } \\
\qquad \text { (BCG) }\end{array}$} & \multicolumn{2}{|c|}{$\begin{array}{c}\text { Bilateral Group } \\
\text { (UCG) }\end{array}$} & \multirow[t]{2}{*}{ ANOVA } & \multicolumn{3}{|c|}{$\begin{array}{c}\text { Multiple Comparison Tukey HSD } \\
\text { test } \\
\text { (P Value) }\end{array}$} \\
\hline & Mean & SD & Mean & SD & Mean & SD & & CG-UCG & CG-BCG & BCG-UCG \\
\hline \multicolumn{11}{|c|}{ Mandibular fossa parameters } \\
\hline Mandibular fossa height (mm) & 9.63 & 1.69 & 9.56 & 1.12 & 9.43 & 1.14 & 0.842 & 0.984 & 0.854 & 0.889 \\
\hline Mandibular fossa width (mm) & 16.33 & 2.55 & 16.17 & 1.90 & 16.48 & 1.86 & 0.852 & 0.961 & 0.960 & 0.798 \\
\hline \multicolumn{11}{|c|}{ Condylar parameters } \\
\hline \multicolumn{11}{|c|}{ Condylar inclination } \\
\hline Mediolateral $\left({ }^{\circ}\right)$ & 12.49 & 5.39 & 10.55 & 7.39 & 9.24 & 6.30 & 0.150 & 0.481 & 0.091 & 0.745 \\
\hline Vertical $\left({ }^{\circ}\right)$ & 52.63 & 11.57 & 58.10 & 9.51 & 58.59 & 9.18 & 0.05 & 0.122 & 0.078 & 0.977 \\
\hline Anteroposterior $\left({ }^{\circ}\right)$ & 72.34 & 6.57 & 68.15 & 6.43 & 70.10 & 6.16 & 0.044 & 0.040 & 0.365 & 0.462 \\
\hline \multicolumn{11}{|c|}{ Condylar position } \\
\hline Vertical (mm) & 2.07 & 1.30 & 1.79 & 1.00 & 1.56 & 1.02 & 0.220 & 0.629 & 0.224 & 0.657 \\
\hline Anteroposterior (mm) & 6.47 & 3.13 & 6.60 & 4.17 & 7.16 & 2.27 & 0.689 & 0.989 & 0.592 & 0.797 \\
\hline Mediolateral (mm) & 57.52 & 5.85 & 50.89 & 2.52 & 51.48 & 2.15 & $.000 * * *$ & 0.000 & 0.000 & 0.600 \\
\hline Vertical condylar joint position (mm) & 6.11 & 2.07 & 5.74 & 2.25 & 5.40 & 1.58 & 0.387 & 0.793 & 0.301 & 0.769 \\
\hline AP condylar joint position (\%) & -2.51 & 14.75 & -5.07 & 21.80 & 8.53 & 15.66 & $0.009 * *$ & 0.856 & 0.018 & 0.020 \\
\hline \multicolumn{11}{|c|}{ Condylar dimension } \\
\hline Condylar length (mm) & 18.38 & 1.95 & 17.86 & 3.03 & 17.91 & 2.52 & 0.691 & 0.718 & 0.707 & 0.997 \\
\hline Condylar width (mm) & 8.15 & 0.99 & 7.09 & 1.04 & 6.65 & 1.06 & $0.000 * * *$ & 0.000 & 0.000 & 0.256 \\
\hline Condylar height (mm) & 13.55 & 2.44 & 11.21 & 1.66 & 10.73 & 0.92 & $0.000^{* * *}$ & 0.000 & 0.000 & 0.362 \\
\hline \multicolumn{11}{|c|}{ TM Joint spaces } \\
\hline Anterior Joint Space (mm) & 2.68 & 0.63 & 2.47 & 0.84 & 2.13 & 0.43 & $0.007 * *$ & 0.520 & 0.001 & 0.135 \\
\hline Posterior joint space (mm) & 2.69 & 0.63 & 2.22 & 0.71 & 2.59 & 0.713 & $0.023^{*}$ & 0.024 & 0.836 & 0.116 \\
\hline
\end{tabular}

This article is protected by copyright. All rights reserved 


\begin{tabular}{|c|c|c|c|c|c|c|c|c|c|c|}
\hline Superior joint space $(\mathrm{mm})$ & 3.37 & 0.85 & 2.87 & 0.74 & 2.91 & 0.72 & $0.023 *$ & 0.045 & 0.065 & 0.980 \\
\hline Medial joint space (mm) & 2.69 & 0.86 & 2.89 & 1.01 & 3.00 & 0.71 & 0.368 & 0.681 & 0.278 & 0.874 \\
\hline Whole joint space $\left(\mathrm{mm}^{3}\right)$ & 318.91 & 37.34 & 266.48 & 46.27 & 309.14 & 61.43 & $0.000 * * *$ & 0.000 & 0.739 & 0.010 \\
\hline
\end{tabular}

SD indicates standard deviation; ANOVA, analysis of variance.

$* \mathrm{P}<.05 ; * * \mathrm{P}<.01 ; * * * \mathrm{P}<.001$

This article is protected by copyright. All rights reserved 

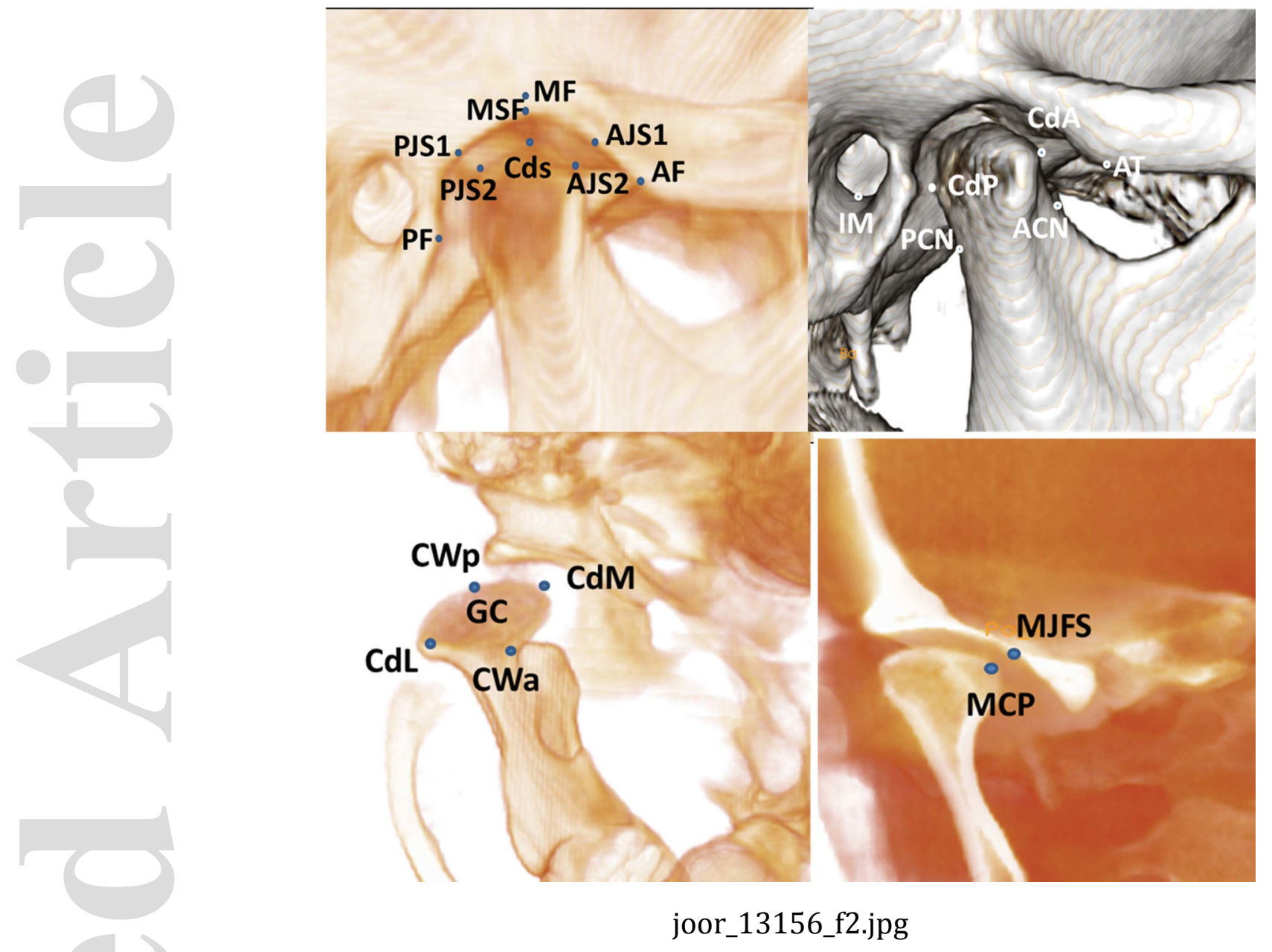

This article is protected by copyright. All rights reserved 


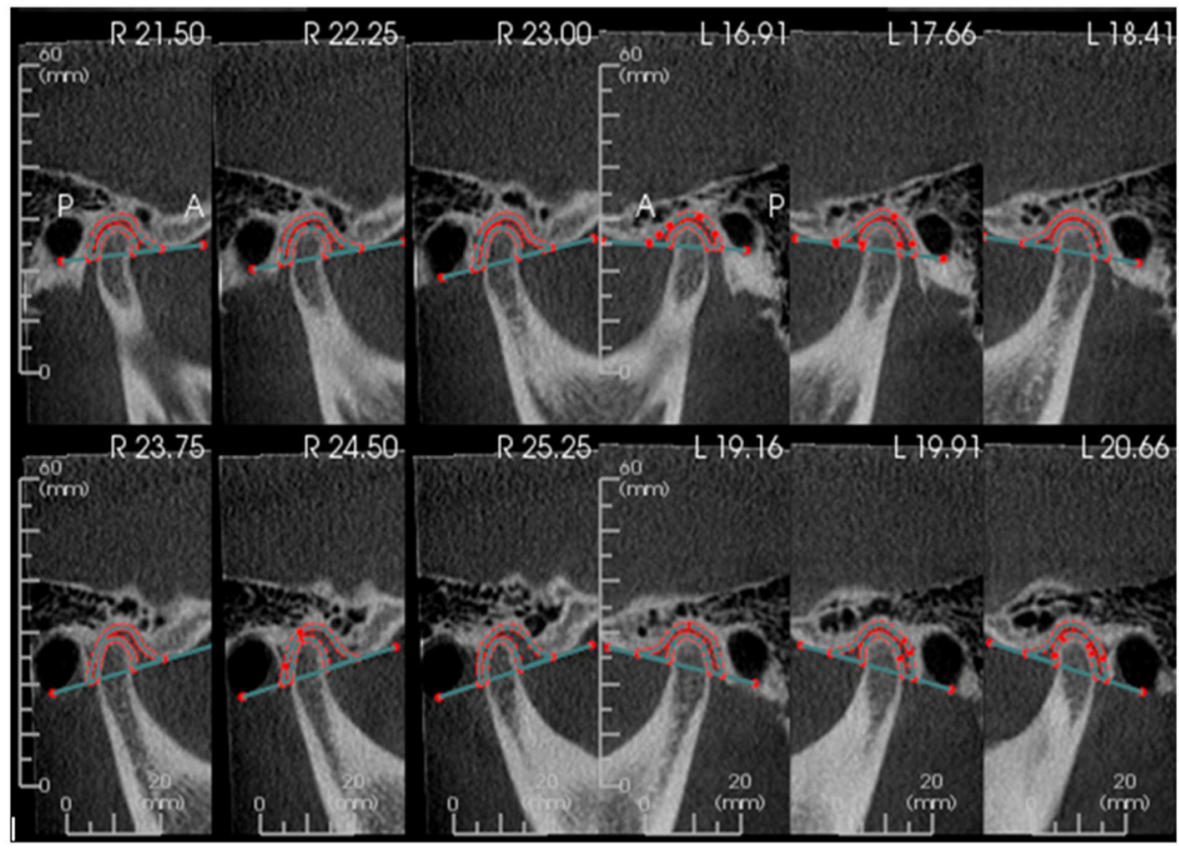

joor_13156_f3.jpg 